\title{
Raising Awareness about Water Issues: The Role of Water Symbolism and Proverbs
}

\author{
Joško Sindik ${ }^{1}$, Yoseph Negusse Araya ${ }^{2}$ \\ ${ }^{1}$ Department of Mathematical Modelling and Biostatistics, Institute for Anthropological Research, Zagreb, Croatia \\ ${ }^{2}$ Department of Geography, Environment and Development Studies, Birkbeck College, University of London, London, UK \\ Email: josko.sindik@inantro.hr
}

Received February 5, 2013; revised March 7, 2013; accepted March 20, 2013

Copyright (C) 2013 Joško Sindik, Yoseph Negusse Araya. This is an open access article distributed under the Creative Commons Attribution License, which permits unrestricted use, distribution, and reproduction in any medium, provided the original work is properly cited.

\begin{abstract}
Sustainable water management is one of the global grand challenges of our time. Tackling this challenge through corrective actions would require the participation of the general public, a public with sound awareness of the challenge and commitment. One such awareness raising intervention could be through the use of water symbolism and proverbs, targeted to particular society. Water has the different symbolism and levels of importance to people, depending of their personal characteristics and socio-demographic factors (e.g. gender, age, occupation, residence). Similarly, water proverbs can also demonstrate attitudes towards water among communities, ethnic groups and whole nations. Such meanings and symbolism could help determine attitude and be a powerful tool towards education. In this context, we describe and propose a psychological Health Belief Model (HBM) as a way to explain behaviour and stimulate sustainable water management practice.
\end{abstract}

Keywords: Health Behavior; Health Belief Model; Water Proverbs; Water Symbolism; Public Education

\section{Introduction}

The world faces severe and growing challenges in maintaining water quality and meeting the rapidly growing demand for water resources [1]. One of the key challenges in implementing corrective actions is lack of awareness and capability among the general public [2]. This calls for targeted and often creative approaches to engage society. Supporting community actions and intervening through behavioral change programs have been known to drive society towards an ecologically sustainable life style and work practices. Some examples are awareness in waste prevention, water pollution, climate change and biodiversity conservation [3]. Therefore educating and empowering people to become active agents of sustainable and equitable development would be an important step towards a better global future [4]. In this connection, water education is a key theme of the International Hydrological Programme and considered a strategic starting point in developing a new ethic for water governance and management [5].

Solving water problems starts with scientific assessment and risk analysis, then with public education and finally with shaping of appropriate political action [6]. In addition, to policy makers who are directly involved in planning water resources development, allocation, and management, decisions have to be made together with the rest of the water users: citizens and scientific experts. In this context, raising awareness about water issues is thus a main pre-assumption for constructive public participation during specific decisions about water management and water protection.

However, there are many challenges in providing water education for sustainable development. In spite of the wide range of materials and projects focusing on water-related education, not infrequently there are shortcomings including: lack of adaptation in offering specific solutions to individual locations and communities; challenges in communication targeting, lack of integration with the wider curriculum and local knowledge; and weak linkages with locally available professional bodies [5]. Especially when dealing with indigenous knowledge, it is to be noted that such water knowledge for example may have to be modified or rebuilt, or simply accepted.

In this paper, we focus on how meanings of water (communicated via proverbs and symbolism) can influence individuals and communities' behaviour and practice of water management. 


\section{Meanings of Water}

The meanings of water for certain populations can be perceived as one of the key factors in raising awareness about water issues. Water has different levels of importance for different people, depending on their personal characteristics, socio-demographic factors, ethnic or community background. Consequently, one of the main challenges to change a wide range of undesirable attitudes is the need to successfully change behaviors [7]. Namely, attitudes have cognitive, emotional and behavioral component and a key target for raising awareness can be behavioral change. Changed behavior can then lead people to better and more constructive public participation.

One way on how to change behaviors of certain population, discussed in this article is, adapting a model called Health Belief Model [8]. This model, imported from health psychology can be used in attempts to change destructive water behavior, as well as to promote responsible public participation. But prior to this, a background discussion on water symbolism and proverbs is provided as follows.

\subsection{Symbolism of Water}

Identification of differences in the perception of symbolic values of water to various people, can lead us to get better insight why the term "water" has different meaning to each individual. Certain individuals are inclined to appreciate and care about the value of fresh water, while the others can only watch water issues at a distance, symbolically [9].

A study was performed to explore the differences and correlates among different symbolic values of water and selected demographic and socio-economic characteristics. The snowball sample $(\mathrm{N}=137)$ of people in Croatia was examined, using preliminary list of 40 possible symbolic meanings of water. Subjects then had to show how much certain symbolism of water is characteristically important to them. The results of principal component analysis (PCA) with varimax rotation showed the existence of three latent dimensions that best represent three symbolic values of water drawn out from the preliminary list namely, abstract, concrete and identity value. Abstract values of water were described as very global ontological, mythological and religious meanings. Concrete values of water were described as dominantly associations that were directly linked with fresh water and its practical use, challenges, dangers, opportunities. The third latent dimension was the most interesting. This, so-called identity value of water represents the symbolism of national and regional affiliation, together with astrological meaning of water that was probably linked with personal identity. Correlations were then undertaken between latent dimensions (symbolic meanings of water) and certain vari- ables: age, work experience and education level. Only small numbers of statistically significant correlations were found: e.g. positive statistically significant correlations showed that abstract values of water are more frequent with older subjects having longer work experience. On the latent dimensions of symbolic meanings of water, very small numbers of statistically significant differences were found according to participants' gender, type of the profession and regional affiliation. Abstract meanings of water were more significant for women, while the symbolic meanings of water as identity were more significant for e.g. to participants born near the sea [9]. The Appendix provides list of water terms used and summary of statistical analyses.

\subsection{Water Proverbs}

One of the distinctive features of human society is possession of "culture" i.e. a developed sense of knowledge, beliefs and expectations which is shared and inherited at various levels of their social organization. One such manifestation is the existence of vast amount of cultural references, through customs, religion, and folklore. Proverbs are a most common example of this oral culture.

Simply defined a proverb means "a short sentence, usually in a figurative expression, expressing well known truths, social norms, or moral themes in common use by a society or social group" [10]. Many proverbs are rooted in a country's ancient cultural heritage or religion, while others may have literary origin, as used by famous people, or may stem from memorable incidents in the past.

Proverbs are an essential part of the oral culture of a society, and are frequently used to define the environment and experiences of a particular society. As water, influences all aspects of life, it is a frequent subject of proverbs and can be found in many cultures.

The existence of similar kinds of proverbs in different languages suggests that some conceptions of intelligence and reasonable behaviour are to some degree universal [11]. Thus sharing proverbs between different cultures will also help in developing some degree of universal appreciation and awareness towards "super culture" and help in building cross-cultural dialogue for peace and security, as mentioned in UNESCO's Universal Declaration of Cultural Diversity, 2001.

In this context, 517 proverbs across 104 different languages and cultures containing the term "water" were examined from an online database [12]. This database is the most complete available and concurs with public collections made previously by the author (YNA) [13].

The proverbs were then analysed by considering the key water theme (metaphorically or otherwise) they are addressing [14]. This approach had proven to be useful, when comparing across cultures in the past. 
The investigation results showed incidences of frequently encountered proverbs from many languages but across two themes. The first one dealt with the importance of protecting water resources. In this context, the most common proverb noted "Do not spit in to a well which you may drink later". The second theme was, on the importance of using the water one has wisely, as exemplified with the proverb "We only appreciate the value of water, when the well is dry".

Overall, such universal themes indicate, the importance of water management across cultures. Moreover, coupled with appreciation to one's own cultural heritage, they could be powerful vehicles to carry wise water management messages to their respective communities.

\section{From Health Belief Model to Water Belief Model?}

Health Belief Model (HBM) has been previously used in attempts to explain and predict health behaviors: through focus on the attitudes and beliefs of individuals about health [15]. Although it was originally developed in response to the failure of a free tuberculosis health screening program [8], it has since been used for sexual risk behaviours and HIV/AIDS pandemics. Through this arti- cle, we suggest HBM can also be applied in water education for the purpose of raising environmental awareness. An example of the core assumptions and statements of HBM, as applied to water issues are shown in see Table 1.

For practical application purposes, the HBM could further be described in terms constructs representing the perceived threats and benefits: perceived susceptibility, perceived severity, perceived benefits, and perceived barriers. Further two concepts building on the above readiness to act i.e. cues to action (cues activate readiness for action and stimulate overt behavior); and selfefficacy (i.e. confidence of the individual that he/she has the ability to successfully perform a better action) could extend the models application [8]. Table 2 describes these, as applied to the water health model.

\section{Conclusion}

The studies in this show that water proverbs and symbolism can give insight into societal attitudes towards water. As part of this, they could raise awareness via behavioral change, stimulating more constructive and responsible behavior toward topical water management issues. As such they could point towards an important potential

Table 1. Health belief model and water belief model depiction on when a person undertakes a respective action.

\begin{tabular}{ll}
\hline Health Belief Model & Water Belief Model \\
\hline feels that a negative health condition (i.e., HIV) can be avoided & $\begin{array}{l}\text { feels that a negative water condition (i.e. scarcity of drinking water) can be } \\
\text { avoided }\end{array}$ \\
$\begin{array}{l}\text { has a positive expectation that by taking a recommended action, he/she } \\
\text { will avoid a negative health condition (i.e., using condoms will be } \\
\text { effective at preventing HIV) }\end{array}$ & $\begin{array}{l}\text { has a positive expectation that by taking a recommended action, he/she will } \\
\text { available for drinking) }\end{array}$ \\
$\begin{array}{l}\text { believes that he/she can successfully take a recommended health action } \\
\text { (i.e., he/she can use condoms comfortably and with confidence) }\end{array}$ & $\begin{array}{l}\text { believes that he/she can successfully take a recommended water action (i.e. } \\
\text { he/she will use water saving techniques to ensure scarcity of drinking water } \\
\text { at home) }\end{array}$
\end{tabular}

Table 2. Application to water belief model from constructs of health belief model (adapted from [16]).

\begin{tabular}{|c|c|c|}
\hline Concept & Definition & Application in water issues \\
\hline Perceived Susceptibility & One's opinion of chances of getting a condition & $\begin{array}{l}\text { Define population(s) at risk, risk levels; personalized risk based on } \\
\text { a person's features or behavior; heighten perceived susceptibility } \\
\text { if too low }\end{array}$ \\
\hline Perceived Severity & $\begin{array}{l}\text { One's opinion of how serious a condition and } \\
\text { its consequences are }\end{array}$ & $\begin{array}{l}\text { Specify consequences of the water risk and the current (perceived) } \\
\text { condition }\end{array}$ \\
\hline Perceived Benefits & $\begin{array}{l}\text { One's belief in the efficacy of the advised action to } \\
\text { reduce risk or seriousness of impact }\end{array}$ & $\begin{array}{l}\text { Define what action has to be taken by an individual, how, where and } \\
\text { when; clarify the positive effects to be expected }\end{array}$ \\
\hline Perceived Barriers & $\begin{array}{l}\text { One's opinion of the tangible and psychological } \\
\text { costs of the advised action }\end{array}$ & $\begin{array}{l}\text { Identify and reduce barriers through reassurance, incentives, } \\
\text { assistance }\end{array}$ \\
\hline Cues to Action & Strategies to activate "readiness" & $\begin{array}{l}\text { Provide how - to information, promote awareness, and invent } \\
\text { reminders }\end{array}$ \\
\hline Self-Efficacy & Confidence in one's ability to take action & Provide training, guidance in performing action. \\
\hline
\end{tabular}


where as part of an education exercise, they could contribute to conservation endeavours. To this end the attempt to translate an established Health Belief Model into a practical Water Belief Model, with potential applications is recommended.

\section{REFERENCES}

[1] UNESCO, "World Water Development Report: Managing Water Uncertainty and Risk," 2012.

[2] Y. N. Araya and V. Kabakian, "Young Peoples Involvement in Global Water Issues," Futures, Vol. 36, No. 5, 2004, pp. 603-609.

doi:10.1016/j.futures.2003.10.010

[3] Environment Directorate "Environmental Awareness Strategy 2010-2015," Cork County Council, 2010. http://www.corkcoco.ie/co/pdf/828098920.pdf

[4] Y. N. Araya and E. H. Moyer, "Global Public Water Education: The World Water Monitoring Day Experience," Journal of Applied Environmental Education and Communication, Vol. 5, No. 4, 2006, pp. 263-267. doi:10.1080/15330150601059522

[5] IHP, "Water Education for Sustainable Development," UNESCO, International Hydrological Programme (IHP) -Division of Water Sciences, Paris, 2012.

[6] P. H. Raven, L. R. Berg and G. B. Johnson, "Environment," Saunders College Publishing, Orlando, 1993.

[7] M. Stead, R. Gordon, I. Holme, C. Moodie, G. Hastings and K. Angus, "Changing Attitudes, Knowledge and Behaviour: A Review of Successful Initiatives," Joseph Rowntree Foundation, University of Stirling, Stirling,
2009.

[8] C. A. Redding, J. S. Rossi, S. R. Rossi, W. F. Velicer and J. O. Prochaska, "Health Behavior Models," The International Electronic Journal of Health Education, Vol. 3, 2000, pp. 180-193.

[9] J. Sindik, "How Do Different People Perceive Symbolic Values of the Water-An Interdisciplinary Approach," Water: Unite and Divide Interdisciplinary Approaches for a Sustainable Future, European Science Foundation, Stresa, 27-30 August 2012.

[10] W. Mieder, "Popular Views of the Proverb," De Proverbio, Vol. 5, No. 2, 1999, pp. 109-144.

[11] R. W. Gibbs Jr. "Proverbial Themes We Live by," Poetics, Vol. 29, No. 3, 2001, pp. 167-188. doi:10.1016/S0304-422X(01)00041-9

[12] Anon, "Inspirational Proverbs, Quotes, Sayings," 2013. http://www.inspirationalstories.com/proverbs/t/on-water/

[13] UNESCO, "World Water Day 2006: Water Proverbs," 2013.

http://webworld.unesco.org/water/wwd2006/world_views /water_language.shtml

[14] J. Charteris-Black, “'Still Waters Run Deep' Proverbs about Speech and Silence: A Cross-Linguistic Perspective," De Proverbio, Vol. 1, No. 2, 1995, p. 352.

[15] M. Conner and P. Norman, "Predicting Health Behavior. Search and Practice with Social Cognition Models," Open University Press, Buckingham, 1996.

[16] K. Glanz, B. K. Rimer and S. M. Su, "Theory at a Glance: A Guide for Health Promotion Practice," National Cancer Institute, Bethesda, 1997. 


\section{Appendix}

Table 1. The water symbolism list: descriptive characteristics for the list of symbolic associations about water.

\begin{tabular}{|c|c|c|}
\hline Water Symbolism List & Mean & Std. Deviation \\
\hline astrologic symbolism & 2.167 & 1.295 \\
\hline swimming pool & 4.575 & 0.798 \\
\hline disease & 2.007 & 1.033 \\
\hline inherent part of everything & 3.807 & 1.181 \\
\hline geometric body & 1.353 & 0.821 \\
\hline global warming & 3.672 & 1.102 \\
\hline intimate relationship & 2.007 & 1.078 \\
\hline source of the life & 4.397 & 0.998 \\
\hline equality of the nations & 1.779 & 1.107 \\
\hline chaos & 1.850 & 1.111 \\
\hline cosmic energy & 2.180 & 1.308 \\
\hline creative principle & 2.096 & 1.145 \\
\hline wisdom & 2.178 & 1.298 \\
\hline national borderlines & 2.541 & 1.252 \\
\hline national identity & 2.133 & 1.171 \\
\hline irrigation & 4.522 & 0.915 \\
\hline non-differentiated & 2.684 & 1.370 \\
\hline lack & 3.415 & 1.242 \\
\hline abundance & 3.135 & 1.386 \\
\hline memory & 1.809 & 1.139 \\
\hline tide & 4.711 & 0.679 \\
\hline beginning of the world & 3.328 & 1.279 \\
\hline concept of a number & 1.419 & 0.794 \\
\hline agriculture & 3.706 & 1.005 \\
\hline overflow & 4.511 & 0.945 \\
\hline predominance & 2.162 & 1.175 \\
\hline transition of life & 2.059 & 1.258 \\
\hline cleaning power & 3.588 & 1.232 \\
\hline regional identity & 2.368 & 1.298 \\
\hline birth & 2.919 & 1.344 \\
\hline self-recovery & 2.918 & 1.472 \\
\hline memory & 2.448 & 1.284 \\
\hline starting power & 3.588 & 1.226 \\
\hline spirituality & 2.348 & 1.318 \\
\hline hygiene resources & 4.459 & 0.944 \\
\hline fear & 2.066 & 1.224 \\
\hline universe & 2.143 & 1.116 \\
\hline fundamental component & 4.304 & 1.046 \\
\hline vibrations & 2.194 & 1.166 \\
\hline water for drinking & 4.888 & 0.501 \\
\hline contaminated & 3.676 & 1.154 \\
\hline life energy & 3.567 & 1.259 \\
\hline knowledge & 1.919 & 1.072 \\
\hline
\end{tabular}

The highest values of means are observed in associations connected with water for drinking, tides and the swimming pool. The highest variations among participants are found in associations connected with self-recovery and abundance. 
Table 2. Pearson's correlations between the dimensions of symbolic meanings of water and socio-demographic variables.

\begin{tabular}{|c|c|c|c|c|c|c|}
\hline Variables & education level & work experience & age & abstract meaning & identity meaning & concrete meaning \\
\hline education level & 1 & & & & & \\
\hline work experience & -0.12 & 1 & & & & \\
\hline age & -0.01 & $0.93^{* *}$ & 1 & & & \\
\hline abstract meaning & 0.01 & $0.26^{* *}$ & $0.24^{* *}$ & 1 & & \\
\hline identity meaning & 0.06 & 0.14 & 0.11 & -0.01 & 1 & \\
\hline concrete meaning & $-0.26^{* *}$ & 0.07 & 0.07 & 0.07 & 0.04 & 1 \\
\hline
\end{tabular}

${ }^{* *}$ Correlation is significant at the 0.01 level (2-tailed); ${ }^{*}$ Correlation is significant at the 0.05 level (2-tailed).

All the three symbolic meanings of water are not significantly inter-correlated, an unavoidable consequence of using Principal Component method for extracting the latent dimensions of the Water Symbolism List (WSL). Among the cross-correlations between the dimensions of symbolic meanings of water and socio-demographic vari- ables, all statistically significant correlations are very low. Positive correlations are found between abstract meaning of water and subjects' age and their work experience, while a negative one is found between concrete meaning of water and subjects' education level. 